\title{
Sesamol: A Natural Phenolic Compound with Promising Anticandidal Potential
}

\author{
Moiz A. Ansari, Zeeshan Fatima, and Saif Hameed \\ Amity Institute of Biotechnology, Amity University, Manesar, Gurgaon, Haryana 122413, India \\ Correspondence should be addressed to Zeeshan Fatima; drzeeshanfatima@gmail.com and Saif Hameed; saifhameed@yahoo.co.in
}

Received 7 August 2014; Revised 20 October 2014; Accepted 21 October 2014; Published 9 December 2014

Academic Editor: Nongnuch Vanittanakom

Copyright (C) 2014 Moiz A. Ansari et al. This is an open access article distributed under the Creative Commons Attribution License, which permits unrestricted use, distribution, and reproduction in any medium, provided the original work is properly cited.

\begin{abstract}
We investigated the antifungal effects of sesamol (Ses), a natural phenolic compound, and exemplified that it could be mediated through disruption of calcineurin signaling pathway in C. albicans, a human fungal pathogen. The repertoire of antifungal activity not only was limited to C. albicans and its six clinical isolates tested but also was against non-albicans species of Candida. Interestingly, the antifungal effect of Ses affects neither the MDR efflux transporter activity nor passive diffusion of drug. We found that $C$. albicans treated with Ses copies the phenotype displayed by cells having defect in calcineurin signaling leading to sensitivity against alkaline $\mathrm{pH}$, ionic, membrane, salinity, endoplasmic reticulum, and serum stresses but remained resistant to thermal stress. Furthermore, the ergosterol levels were significantly decreased by $63 \%$ confirming membrane perturbations in response to Ses as also visualized through transmission electron micrographs. Despite the fact that Ses treatment mimics the phenotype of compromised calcineurin signaling, it was independent of cell wall integrity pathway as revealed by spot assays and the scanning electron micrographs. Taken together, the data procured from this study clearly ascertains that Ses is an effectual antifungal agent that could be competently employed in treating Candida infections.
\end{abstract}

\section{Introduction}

Candida albicans, an opportunistic human fungal pathogen, is the most common cause of the invasive fungal diseases [1]. It resides normally within the host body but during the immunosuppressed or immunocompromised conditions like AIDS, cancer, and organ transplant; it can cause several diseases such as oral thrush, vulvovaginitis, esophagitis, and cutaneous infections. It is also among the most common causative agents for nosocomial infections in patients who have undergone surgery or organ transplantation, have diabetes, and take excessive antibiotics and are neutropenic [2, 3]. Some of the most common isolates from candidiasis and candidemia are C. albicans, Candida glabrata, Candida krusei, Candida tropicalis, and Candida parapsilosis [4]. Among all Candida species C. albicans is the most prominent causative agent of the diseases [5]. Due to daily augmentation in cases of the patients suffering from the diseases caused by Candida species, it has become unavoidable to find the cure for this evader.

Present treatment regime includes several classes of antifungal which are in use to treat the infection caused by the fungal pathogens. For instance azoles, polyenes and allylamines target ergosterol pathway. Echinocandins and pyrimidines target cell wall and nucleic acid synthesis respectively [6]. Due to excessive usage of the current therapeutic drugs, there occur several quandaries associated with these drugs. Multidrug resistance (MDR), severe side effects, high cost, and lesser efficiency are some of the most renowned and sufficient causes for the scientific community to take the initiative steps for finding the newer drugs having lesser toxicity and targeting the new pathways. Natural compounds due to their cost effectiveness and lesser toxicity could prove to be a better option for the new era of the antifungal drug with new targets and better activity.

Sesamol (Ses) (3,4-methylenedioxyphenol) is a wellknown antioxidant which is extracted from the sesame oil from Sesamum species [7]. There are several beneficial effects known for sesamol that have been reported like antioxidant, chemoprevention, antimutagenic, and antihepatotoxic activities and induction of apoptosis of cancer and cardiovascular cells [8]. In this study, we deciphered the antifungal activity of Ses against human fungal pathogen C. albicans as well as various non-albicans species. We found that antifungal 
action of Ses may be linked with hindered calcineurin signaling pathway and disruption of membrane homeostasis. Considering the significance of ergosterol as the target of known antifungal like azoles, Ses could well be used as adjunct to known drugs for better antifungal therapy.

\section{Materials and Methods}

All media chemicals YEPD (yeast extract peptone dextrose), agar, rhodamine 6G (R6G), 2-deoxy-D-glucose (2-DOG), 2,4-dinitrophenol (2,4 DNP), and $n$-heptane, was purchased from HiMedia (Mumbai, India). Sodium chloride $(\mathrm{NaCl})$, calcium chloride $\left(\mathrm{CaCl}_{2}\right)$, lithium chloride $(\mathrm{LiCl})$, potassium chloride $(\mathrm{KCl})$, mannitol, disodium hydrogen orthophosphate, potassium dihydrogen orthophosphate, dipotassium hydrogen orthophosphate, sodium hydroxide, D-glucose, and sodium dodecyl sulphate (SDS) were obtained from Fischer Scientific. Calcofluor white (CFW), Congo red (CR), and sesamol (Ses) were obtained from Sigma Chemical Co. (St. Louis, MO, USA).

2.1. Growth Media and Strains Used. The reference strains of C. albicans used in this study were ATCC 10261 and ATCC 24433. The clinical isolate strains of C. albicans were D1, D2, D4, D7, D18, and D20 and non-albicans species include ATCC 90030 (Candida glabrata), D9 (Candida tropicalis), D11 (Candida parapsilosis), and D46 (Candida krusei). All the strains of Candida albicans were cultured in YEPD broth with the composition of yeast extract $1 \%(\mathrm{w} / \mathrm{v})$, peptone $2 \%(\mathrm{w} / \mathrm{v})$, and dextrose $2 \%(\mathrm{w} / \mathrm{v})$. For agar plates $2 \%(\mathrm{w} / \mathrm{v})$ agar (HiMedia, Mumbai, India) was added to the media. All Candida strains were stored in $30 \%(\mathrm{v} / \mathrm{v})$ glycerol stock at $-80^{\circ} \mathrm{C}$. The cells were freshly revived on YEPD broth and transferred to agar plate. The cells were grown at $30^{\circ} \mathrm{C}$ on agar plate before each study to ensure the revival of the strains.

2.2. Drug Susceptibility Testing. Drug susceptibility was tested using spot assay, minimal inhibitory concentration (MIC), and filter disc assay as described below.

2.3. Spot Assay. Spot assays for the strains were determined using a method as described elsewhere $[9,10]$. Briefly, for the spot assay $5 \mu \mathrm{L}$ of fivefold serial dilutions of each yeast culture (each with cells suspended in normal saline to an $\mathrm{OD}_{600} \mathrm{~nm}$ of 0.1 ) was spotted onto YEPD plates in the absence (control) and presence of the drugs. Growth was not affected by the presence of solvent (methanol/water 2:1) used in the examination (data not shown). Growth difference was measured after incubation at $30^{\circ} \mathrm{C}$ for 48 hours. The concentrations used in this study are specified in figure legends.

2.4. Minimum Inhibitory Concentration (MIC). MIC was determined by broth dilution method as described in method M27-A3 from the Clinical and Laboratory Standards Institute (CLSI) formerly NCCLS [11]. Briefly, $100 \mu \mathrm{L}$ of media was placed at each well of the 96-well plate following the addition of the drug with the remaining media and then was serially diluted. $100 \mu \mathrm{L}$ of cell suspension (in normal saline to an $\mathrm{OD}_{600}$ 0.1) was added to each well of the plate and $\mathrm{OD}_{600}$ was measured after 48 hours at $30^{\circ} \mathrm{C}$. The $\mathrm{MIC}_{80}$ was defined as the concentration at which the $80 \%$ of the growth was inhibited.

2.5. Filter Disc Assay. The filter disc assay was performed as described elsewhere $[9,10,12]$. The drugs were spotted in a volume of $5-10 \mu \mathrm{L}$ at the indicated amount in the figure legends and the diameters of the respective zones of inhibition were measured after incubation of the plates for 48 hours at $30^{\circ} \mathrm{C}$.

2.6. Rhodamine 6G Efflux. The efflux of R6G was determined by using protocol described elsewhere [13]. Briefly, approximately $1 \times 10^{6}$ yeast cells from an overnight-grown culture in the absence (control) and presence of Ses at its subinhibitory concentration $(0.552 \mathrm{mg} / \mathrm{mL})$ determined by the growth curve experiments (data not shown) were transferred to YEPD medium and allowed to grow for $5 \mathrm{~h}$. Cells were pelleted, washed twice with phosphate-buffered saline (PBS) (without glucose), and resuspended as a $2 \%$ cell suspension, which corresponds to $10^{8}$ cells (w/v) in PBS without glucose. The cells were then deenergized for $1 \mathrm{~h}$ in 2-DOG $(5 \mathrm{mM})$ and 2,4 DNP (5 mM) in PBS (without glucose). The deenergized cells were pelleted, washed, and then resuspended as a $2 \%$ cell suspension (w/v) in PBS without glucose, to which R6G was added at a final concentration of $10 \mu \mathrm{M}$ and incubated for $40 \mathrm{~min}$ at $30^{\circ} \mathrm{C}$. The equilibrated cells with $\mathrm{R} 6 \mathrm{G}$ were then washed and resuspended as a $2 \%$ cell suspension $(\mathrm{w} / \mathrm{v})$ in PBS without glucose. Samples with a volume of $1 \mathrm{~mL}$ were withdrawn at the indicated time and centrifuged at 10,000 $\times \mathrm{g}$ for $1 \mathrm{~min}$. The supernatant was collected, and absorption was measured at $527 \mathrm{~nm}$. Energy dependent efflux (at the indicated time) was measured after the addition of glucose (2\%) to the cells resuspended in PBS (without glucose). Glucose-free controls were included in all the experiments.

2.7. Passive Diffusion of Drug. The passive diffusion of R6G was determined using protocol described elsewhere [12]. Briefly, the cells cultured overnight at $30^{\circ} \mathrm{C}$ in the absence (control) and presence of Ses at its subinhibitory concentration were harvested, washed, and resuspended in $2 \%$ cell suspension with PBS containing $5 \mathrm{mM}$ 2-DOG and $5 \mathrm{mM} \mathrm{2,4}$ DNP for $1 \mathrm{~h}$ to deenergize the cells. After that, the deenergized cells were harvested by centrifugation at $5000 \mathrm{~g} \mathrm{rpm}$ for $3 \mathrm{~min}$. The cells were then pelleted, washed, and resuspended in PBS 2\% (w/v) with the fluorescent compound $10 \mu \mathrm{M}$ R6G for $40 \mathrm{~min}$ and then the cells were harvested at $5000 \mathrm{~g} \mathrm{rpm}$ for $3 \mathrm{~min}$, washed, and mixed with PBS (w/o glucose). The cells were then centrifuged at $10,000 \mathrm{~g} \mathrm{rpm}$ for $1 \mathrm{~min}$ and $\mathrm{OD}_{527}$ of the supernatant from 0 min up until 45 min was measured at the indicated time points in Figure 3.

2.8. Phenotypic Susceptibility Assays. Phenotypic susceptibilities were measured using spot assays as described above. The following stock solutions were used (the solvents used are given in parenthesis): SDS, $10 \% \mathrm{w} / \mathrm{v}$ (water), $\mathrm{NaCl} 5 \mathrm{M}$ (water), $\mathrm{LiCl} 5 \mathrm{M}$ (water), $\mathrm{CaCl}_{2} 5 \mathrm{M}$ (water), and DTT $1 \mathrm{M}$ 
(water). The final chemical concentrations used for this study are specified below. Cells were spotted on YEPD plates in the absence (control) and presence of the Ses at its subinhibitory concentration and the chemicals at the following concentrations: alkaline $\mathrm{pH} 10.0$, SDS (0.02\% w/v), $\mathrm{NaCl}(1 \mathrm{M}), \mathrm{LiCl}$ $(0.4 \mathrm{M})$ and $\mathrm{CaCl}_{2}(0.3 \mathrm{M})$, DTT $(20 \mathrm{mM})$, and serum $(50 \%$ $\mathrm{v} / \mathrm{v})$. For alkaline $\mathrm{pH}$, YEPD plates buffered with $155 \mathrm{mM}$ of Tris- $\mathrm{Cl}$ at $\mathrm{pH} 8.0$ and 10 were used. Growth differences were recorded following incubation of the plates for 48 hours at $30^{\circ} \mathrm{C}$.

2.9. Quantitation of Ergosterol. Sterols were extracted by the alcoholic $\mathrm{KOH}$ method and the percentage of ergosterol was calculated as described previously $[14,15]$. Briefly, a single $C$. albicans colony from an overnight YPD agar plate culture was used to inoculate $50 \mathrm{~mL}$ of YPD in presence and absence of Ses. The cultures were incubated for $16 \mathrm{~h}$ with shaking at $30^{\circ} \mathrm{C}$. The stationary-phase cells were harvested by centrifugation at 2,700 rpm for $5 \mathrm{~min}$ and washed once with sterile distilled water. The net wet weight of the cell pellet was determined to which $3 \mathrm{~mL}$ of freshly prepared $25 \%$ alcoholic potassium hydroxide solution $(25 \mathrm{~g}$ of $\mathrm{KOH}$ and $35 \mathrm{~mL}$ of sterile distilled water, brought to $100 \mathrm{~mL}$ with $100 \%$ ethanol) was added to each pellet and vortex mixed for $1 \mathrm{~min}$. Cell suspensions were transferred to sterile borosilicate glass screw-cap tubes and were incubated in an $85^{\circ} \mathrm{C}$ water bath for $1 \mathrm{~h}$. Following incubation, tubes were allowed to cool to room temperature. Sterols were then extracted by addition of a mixture of $1 \mathrm{~mL}$ of sterile distilled water and $3 \mathrm{~mL}$ of $n$-heptane followed by vigorous vortex mixing for $3 \mathrm{~min}$. The heptane layer was transferred to a clean borosilicate glass screw-cap tube and stored at $-20^{\circ} \mathrm{C}$. Both ergosterol and 24(28)-DHE absorbs at $281.5 \mathrm{~nm}$, whereas only 24(28)-DHE absorb at $230 \mathrm{~nm}$. Ergosterol content is determined by subtracting the amount of 24(28)-DHE (calculated from the $\mathrm{OD}_{230}$ ) from the total ergosterol plus 24(28)-DHE content (calculated from the $\left.\mathrm{OD}_{281.5}\right)$. Ergosterol content was calculated as a percentage of the wet weight of the cells with the following equations: $\%$ ergosterol $+\%$ 24(28) $-\mathrm{DHE}=[(\mathrm{A} 281.5 / 290) \times F] /$ pellet weight; \% 24(28)-DHE $=[(\mathrm{A} 230 / 518) \times F] /$ pellet weight and $\%$ ergosterol $=[\%$ ergosterol $+\% 24(28)$ DHE $]-\% 24(28)$ DHE, where $F$ is the factor for dilution in petroleum ether and 290 and 518 are the $E$ values (in percent per centimeter) determined for crystalline ergosterol and 24(28)-DHE, respectively.

2.10. Electron Microscopy of Candida Cells. Cells treated with Ses at its $\mathrm{MIC}_{80}$ value were observed by using SEM (Zeiss EVOMA10) and TEM (JEOL JEM-1011). The cells ( $\sim 10^{6}$ cells) were administered to the media with and without Ses and were incubated for $24 \mathrm{~h}$ at $30^{\circ} \mathrm{C}$. Sample preparation and analysis were performed by using the method as described elsewhere [16, 17]. Briefly, all cells were fixed with $2 \%$ glutaraldehyde in $0.1 \%$ phosphate buffer for $1 \mathrm{~h}$ at room temperature $\left(20^{\circ} \mathrm{C}\right)$, washed with $0.1 \mathrm{M}$ phosphate buffer $(\mathrm{pH}$ 7.2), and postfixed with $1 \% \mathrm{OsO}_{4}$ in $0.1 \mathrm{M}$ phosphate buffer for $1 \mathrm{~h}$ at $4^{\circ} \mathrm{C}$. Then the cells were dehydrated in acetone, dropped on round glass coverslip with hexamethyldisilazane (HMDS),
TABLE 1: $\mathrm{MIC}_{80}$ of C. albicans and non-albicans species in presence of Ses.

\begin{tabular}{lc}
\hline Strains & MIC $_{80}(\mathrm{mg} / \mathrm{mL})$ \\
\hline ATCC10261 & 1.104 \\
ATCC24433 & 1.104 \\
D1 & 0.828 \\
D2 & 0.828 \\
D4 & 0.828 \\
D7 & 1.104 \\
D18 & 1.104 \\
D20 & 1.104 \\
C. krusei & 1.104 \\
C. glabrata & 1.104 \\
C. parapsilosis & 1.104 \\
C. tropicalis & 1.104 \\
\hline
\end{tabular}

dried at room temperature, and then sputter coated with gold and observed under the SEM (Zeiss EVOMA10) at $30 \mathrm{~K}$ magnificationand TEM (JEOL JEM-1011) at $10 \mathrm{~K}$ magnification.

\section{Results}

3.1. Ses Acts as Effective Antifungal against C. albicans and Non-albicans Species. To analyze the effect of Ses against $C$. albicans we firstly verify its antifungal activity by drug susceptibility testing by several autonomous methods, namely, spot assay, disc diffusion assay, and determining minimum inhibitory concentration $\left(\mathrm{MIC}_{80}\right)$ through broth microdilution assay. Through susceptibility testing it was confirmed that Ses was showing the antifungal activity against $C$. albicans. Through both spot assay (Figure 1(a)) and filter disc assay (Figure 1(b)) it was observed that Ses was inhibiting the growth of C. albicans (ATCC10261, ATCC24433) at $1.104 \mathrm{mg} / \mathrm{mL}$ concentration. Broth microdilution assay also corresponds to the above results and depicts the antifungal effect of Ses (Figure 1(c)). To further test the efficacy of Ses we also performed these tests and estimated the susceptibility of Ses on six different clinical isolates of C. albicans (D1, D2, D4, D7, D18, and D20). We observed that the inhibitory concentration of Ses lies in the range of $0.828-1.104 \mathrm{mg} / \mathrm{mL}$. To further elaborate our study, we extend our drug susceptibility testing against non-albicans species as well, namely, $C$. krusei, C. tropicalis, C. parapsilosis, and C. glabrata. We found that Ses was equally effective against all the tested species of Candida as depicted by spot, filter, and broth microdilution assays (Figures 2(a), 2(b), and 2(c)). Thus, all the drug susceptibility testing results indicate that Ses is inhibitory against reference and clinical isolates of C. albicans as well as non-albicans species (Table 1).

\subsection{Antifungal Activity of Ses Is Independent of Multidrug} Efflux Transporter Activity. Hyperactive efflux pumps are one of the major mechanisms responsible for the development multidrug resistance in the Candida [6]. To verify whether the antifungal activity of Ses is due to hindrance in efflux 


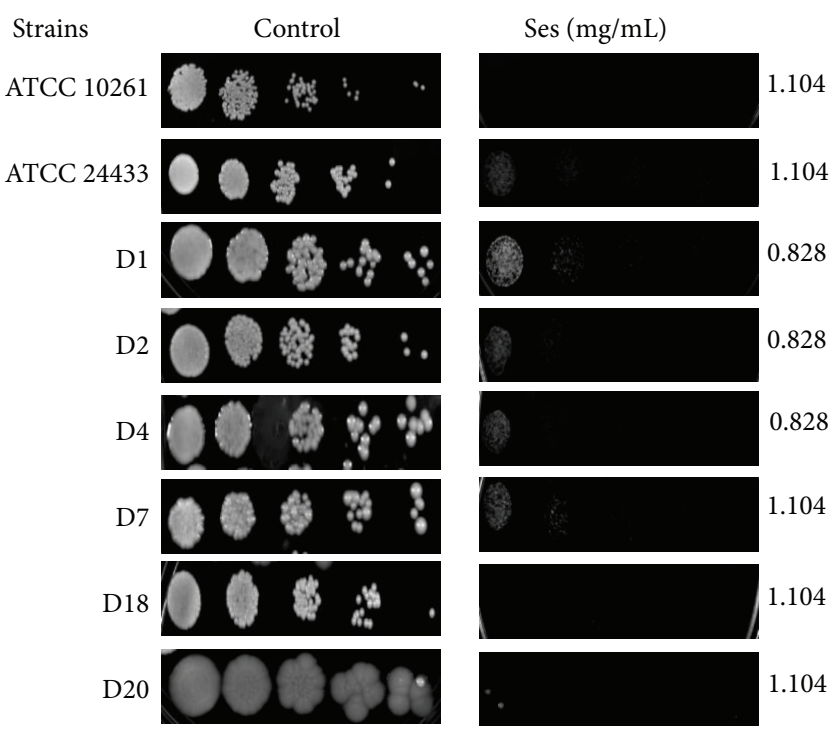

(a)

Conc. $(\mathrm{mg} / \mathrm{mL}) \longrightarrow$

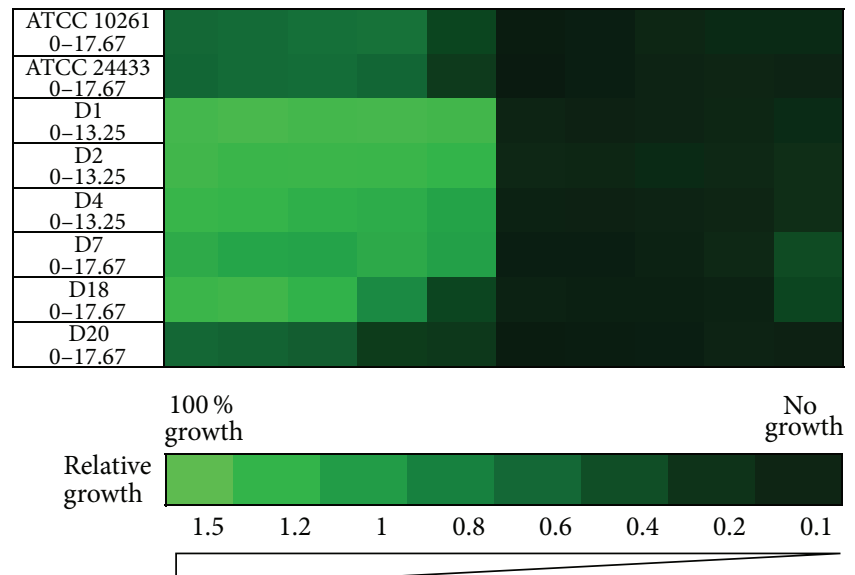

(c)
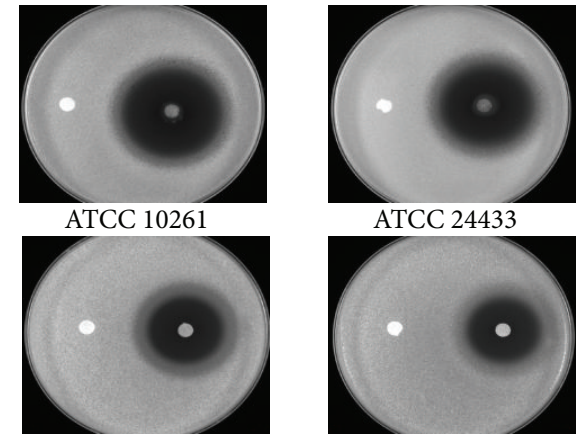

ATCC 24433

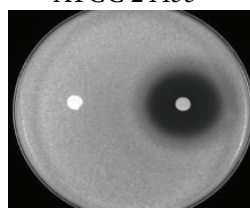

D1

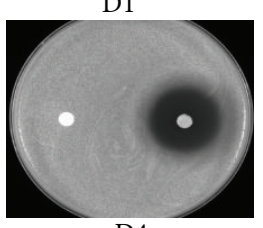

D4

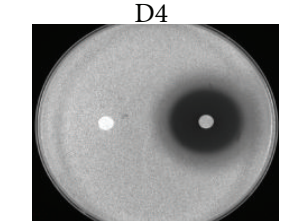

D18
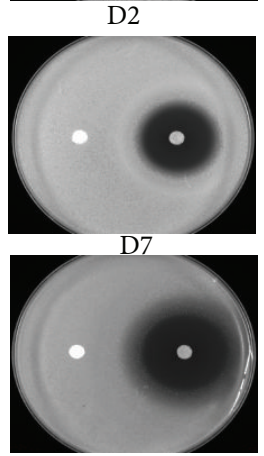

D20

\begin{tabular}{|c|c|c|c|}
\hline \multirow{2}{*}{ Species } & Conc. & \multicolumn{2}{|c|}{ Zone of inhibition $(\mathrm{cm})$} \\
$(\mathrm{mg} / \mathrm{mL})$ & Control & Ses \\
\hline $\begin{array}{c}\text { C. albicans } \\
\text { (ATCC 10261) }\end{array}$ & 1.104 & 0 & 2.2 \\
\hline $\begin{array}{c}\text { C. albicans } \\
\text { (ATCC 24433) }\end{array}$ & 1.104 & 0 & 2.2 \\
\hline D1 & 0.828 & 0 & 3.6 \\
\hline D2 & 0.828 & 0 & 2.8 \\
\hline D4 & 0.828 & 0 & 2.8 \\
\hline D7 & 1.104 & 0 & 2.8 \\
\hline D18 & 1.104 & 0 & 2.6 \\
\hline D20 & 1.104 & 0 & 4 \\
\hline
\end{tabular}

(b)

FIGURE 1: Drug susceptibility assays against C. albicans in the presence of Ses. (a) Spot assay of C. albicans reference strains (ATCC 10261, ATCC 24433) and clinical isolates (D1, D2, D4, D7, D18, and D20) in the absence (control) and presence of Ses. (b) Disc diffusion assay against C. albicans reference strains (ATCC 10261, ATCC 24433) and clinical isolates (D1, D2, D4, D7, D18, and D20) of C. albicans and their respective zone of inhibitions in the absence (control) and presence of Ses. For control, discs were spotted with the solvent of Ses described in Section 2. (c) Broth microdilution assay to determine the $\mathrm{MIC}_{80}$ of C. albicans reference strains (ATCC 10261, ATCC 24433) and clinical isolates (D1, D2, D4, D7, D18, and D20) in presence of Ses. Data was quantitatively displayed with colour (see colour bar), where each shade of colour represents relative optical densities of the cell. The minimum drug concentration that inhibits growth by $80 \%$ relative to the drug-free growth control is indicated as $\mathrm{MIC}_{80}$ for each strain.

pumps activity or not, R6G (known substrate of efflux pumps) efflux assay was performed in presence and absence (control) of Ses. Our data confirmed that there was no significant difference $(P$ value $>0.5)$ in the R6G efflux estimated by extracellular R6G concentration in the absence or presence of Ses (Figure 3(a)). We further accessed whether antifungal activity of Ses could be attributed to enhanced passive diffusion. Our results depict that there was no significant difference ( $P$ value $>0.5$ ) in the passive diffusion of Ses in comparison to the control cells without Ses treatment (Figure 3(b)). Thus, the effect of Ses on C. albicans was independent of the efflux pumps activity and linked with any other pathway.
3.3. C. albicans Was Hypersensitive to Ses at Alkaline pH. C. albicans is an opportunistic fungus that resides in different parts of the body having varying niches. Due to this, it has an imperative ability to overcome such environmental cues. One such significant factor that $C$. albicans needs to cope with is alkaline $\mathrm{pH}$. This exigent activity of Candida spp. compelled us to study the antifungal effect of Ses at alkaline $\mathrm{pH}$ range for C. albicans as well as non-albicans. It was observed that the antifungal activity of Ses was upraised to the level of almost $50 \%$ against $C$. albicans and non-albicans species when spotted at elevated $\mathrm{pH}$ as demonstrated in Figure 4(a). The results were unfaltering with the broth microdilution and disc 


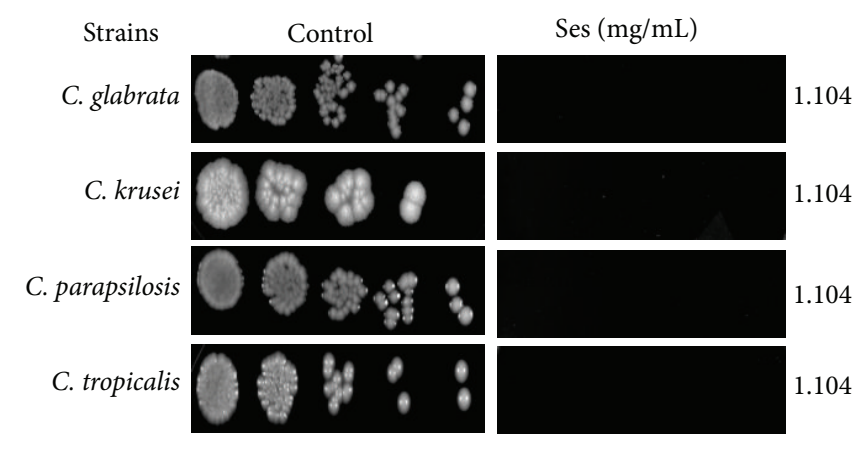

(a)

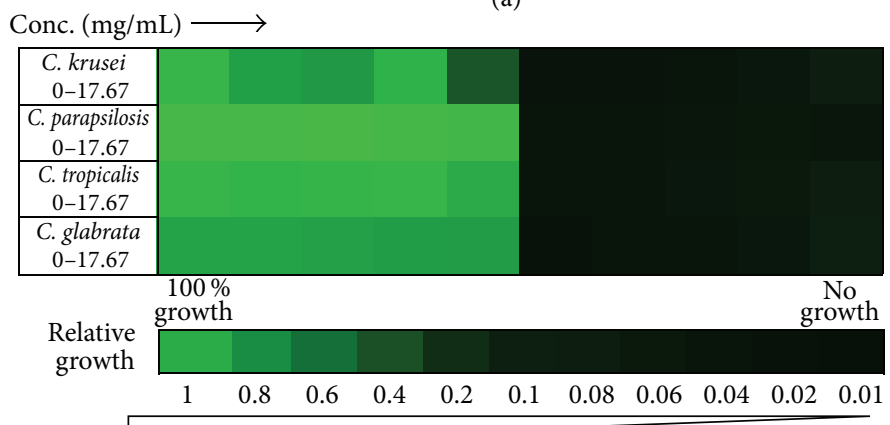

(c)

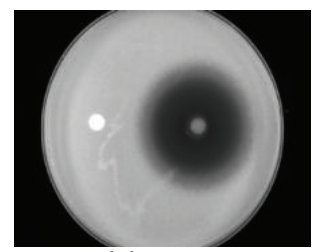

C. glabrata

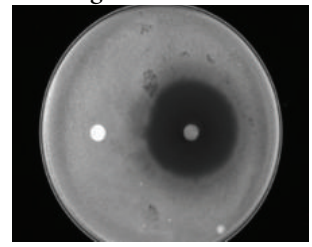

C. parapsilosis

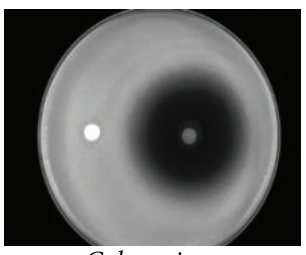

C. krusei

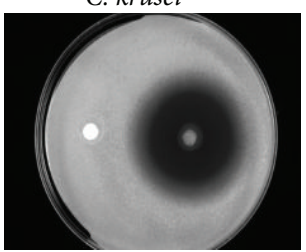

C. tropicalis

\begin{tabular}{|c|c|c|c|}
\hline \multirow{2}{*}{ Species } & \multirow{2}{*}{ Conc. $(\mathrm{mg} / \mathrm{mL})$} & \multicolumn{2}{|c|}{$\begin{array}{c}\text { Zone of inhibition }(\mathrm{cm}) \\
\text { Control }\end{array}$} \\
& & 0 & 3.8 \\
\hline C. glabrata & 1.104 & 0 & 4.0 \\
\hline C. krusei & 1.104 & 0 & 3.4 \\
\hline C. parapsilosis & 1.104 & 0 & 3.6 \\
\hline C. tropicalis & 1.104 & \multicolumn{2}{|c}{} \\
\hline
\end{tabular}

(b)

Figure 2: Drug susceptibility assays against non-albicans species of Candida in the presence of Ses. (a) Spot assay of C. glabrata, C. krusei, C. parapsilosis, and C. tropicalis, in the absence (control) and presence of Ses. (b) Disc diffusion assay against C. glabrata, C. krusei, C. parapsilosis, and C. tropicalis, and their respective zone of inhibitions in the absence (control) and presence of Ses. For control, discs were spotted with the solvent of Ses described in Section 2. (c) Broth microdilution assay to determine the $\mathrm{MIC}_{80}$ of C. glabrata, C. krusei, C. parapsilosis, and C. tropicalis in presence of Ses. Data was quantitatively displayed with colour (see colour bar), where each shade of colour represents relative optical densities of the cell. The minimum drug concentration that inhibits growth by $80 \%$ relative to the drug-free growth control is indicated as $\mathrm{MIC}_{80}$ for each strain.

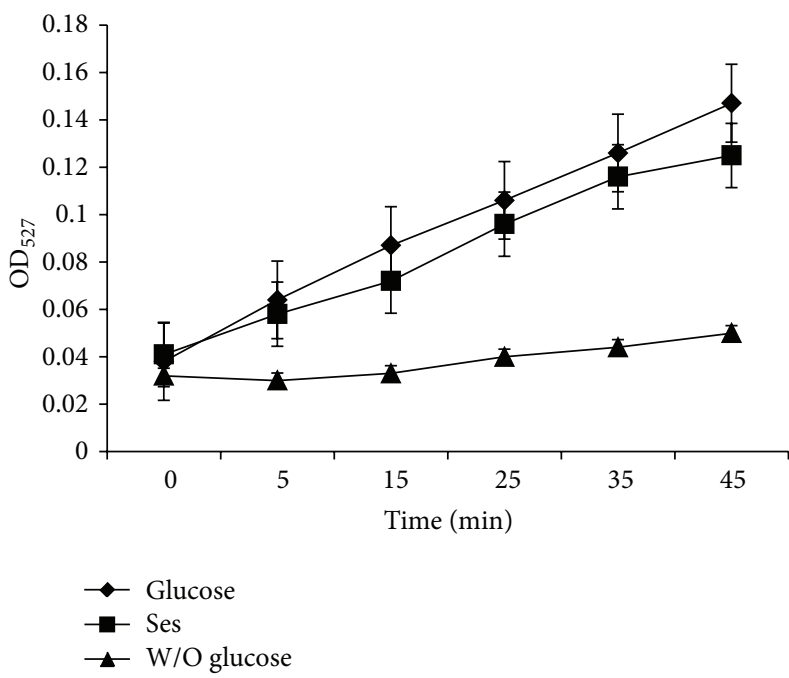

(a)

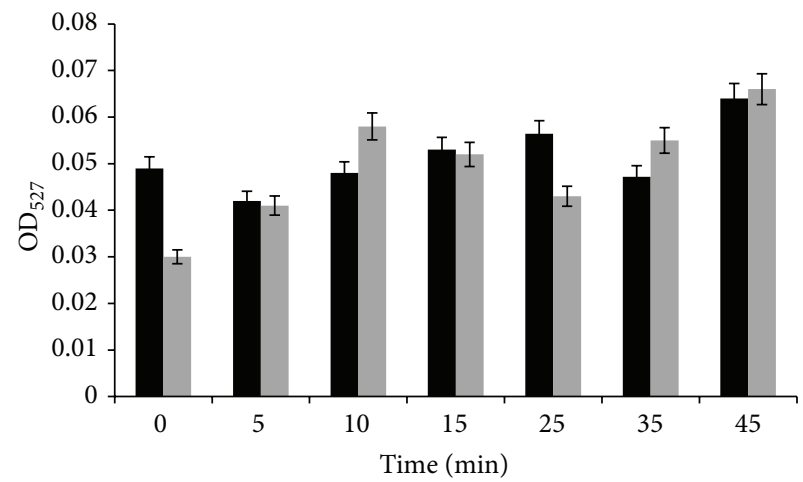

- Control

Ses

(b)

Figure 3: Drug efflux assay and passive diffusion in presence of Ses. (a) Extracellular concentrations of R6G for C. albicans (ATCC 10261) cells grown in absence (control) and presence of Ses $(0.552 \mathrm{mg} / \mathrm{mL})$ calculated as described in material and methods. Negative control represents C. albicans deenergized cells without glucose. Mean of $\mathrm{OD}_{527} \pm \mathrm{SD}$ of three independent sets of experiments are depicted on $y$-axis with respect to time (minutes) on $x$-axis. ( $P$ value $>0.05$ ). (b) Passive diffusion of R6G in absence (control) and presence of $S$ es $(0.552 \mathrm{mg} / \mathrm{mL}$ ) calculated as described in Section 2. Mean of $\mathrm{OD}_{527} \pm \mathrm{SD}$ of three independent sets of experiments are depicted on $Y$-axis with respect to time (minutes) on $x$-axis $(P$ value $>0.05)$. 


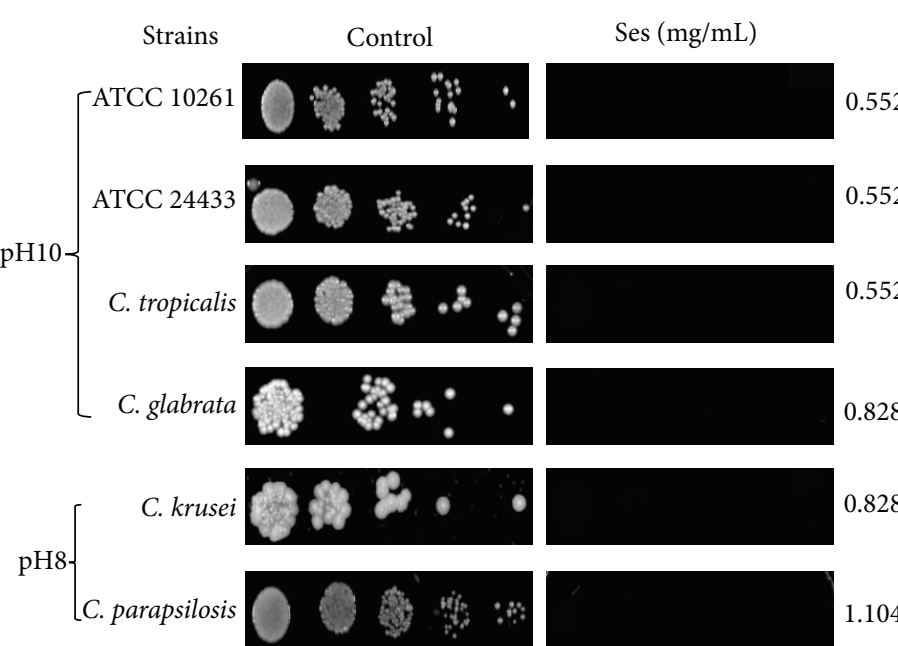

(a)

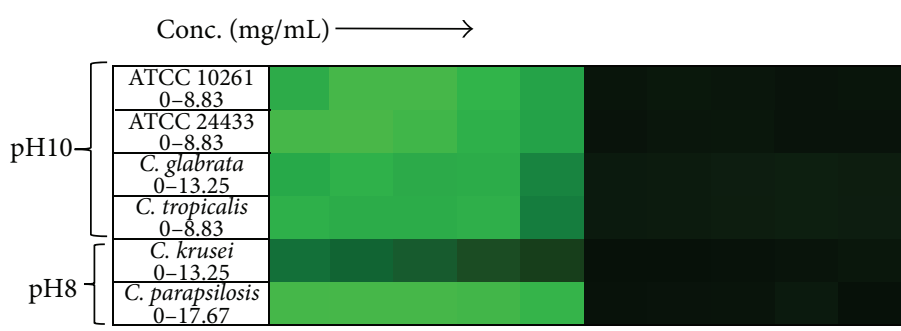

$100 \%$ growth Relative growth
No growth

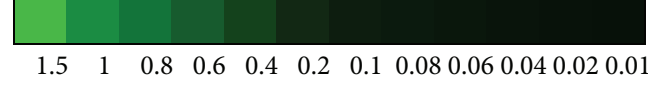

(c)
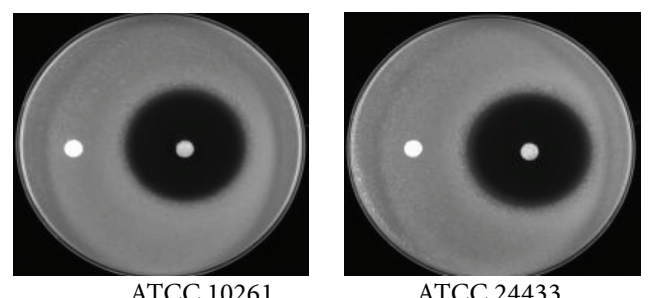

ATCC 24433
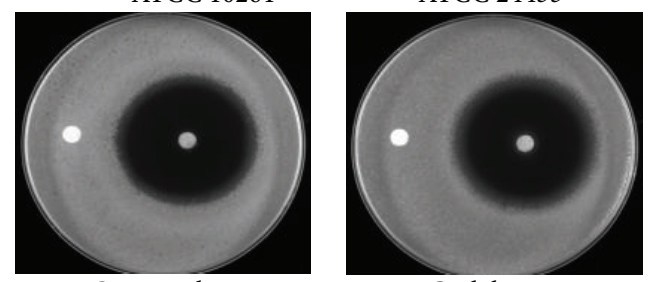

C. tropicalis
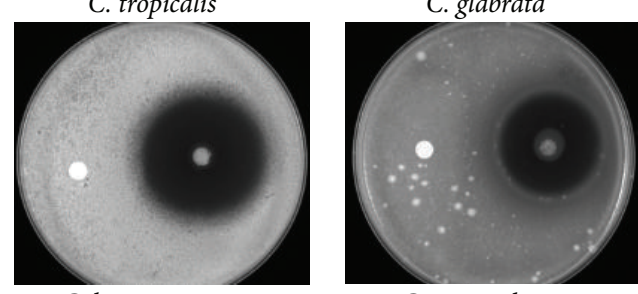

C. parapsilosis

\begin{tabular}{|c|l|c|c|c|}
\hline Species & $\mathrm{pH}$ & \multicolumn{1}{c|}{$\begin{array}{c}\text { Conc. } \\
(\mathrm{mg} / \mathrm{mL})\end{array}$} & \multicolumn{2}{|c|}{$\begin{array}{c}\text { Zone of inhibition } \\
(\mathrm{cm}) \\
\text { Control }\end{array}$} \\
\hline $\begin{array}{c}\text { C. albicans } \\
\text { (ATCC 10261) }\end{array}$ & 10 & 0.552 & 00 & 3.2 \\
\hline $\begin{array}{c}\text { C. albicans } \\
\text { (ATCC 24433) }\end{array}$ & 10 & 0.552 & 00 & 3.4 \\
\hline C. tropicalis & 10 & 0.552 & 00 & 3.8 \\
\hline C. glabrata & 10 & 0.828 & 00 & 3.6 \\
\hline C. krusei & 08 & 0.828 & 00 & 3.2 \\
\hline C. parapsilosis & 08 & 1.104 & 00 & 2.4 \\
\hline
\end{tabular}

(b)

FIgure 4: Drug susceptibility assay against C. albicans and non-albicans speciesat alkaline pH. (a) Spot assay of C. albicans, C. tropicalis, and C. glabrata at $\mathrm{pH} 10$ and C. krusei and C. parapsilosis at pH 8 in the absence (control) and presence of Ses. (b) Disc diffusion assay against C. albicans, C. tropicalis, and C. glabrata at $\mathrm{pH} 10$ and C. krusei and C. parapsilosis at $\mathrm{pH} 8$ and their respective zone of inhibitions in the presence of Ses. For control discs were spotted with the solvent of Ses described in Section 2. (c) Broth microdilution assay to determine the $\mathrm{MIC}_{80}$ at alkaline $\mathrm{pH}$ of C. albicans, C. tropicalis, and C. glabrata at $\mathrm{pH} 10$ and C. krusei and C. parapsilosis at pH 8 in the presence of Ses. Data was quantitatively displayed with colour (see colour bar), where each shade of colour represents relative optical densities of the cell. The minimum drug concentration that inhibits growth by $80 \%$ relative to the drug-free growth control is indicated as $\mathrm{MIC}_{80}$ for each strain.

diffusion assay as well as illustrated in Figures 4(b) and 4(c). All of these results prove that the C. albicans as well as nonalbicans species of Candida becomes hypersensitive to Ses at alkaline $\mathrm{pH}$ (Table 2).

3.4. Ses Phenocopies Compromised Calcineurin Signaling Pathway in C. albicans. Our above results showing hypersensitive response of $C$. albicans at alkaline $\mathrm{pH}$ in presence of Ses prompted us to further study the other phenotypes which were known to be governed by calcineurin signaling. Like alkaline $\mathrm{pH}$ response which is mediated through the calcineurin signaling cascade, we tested the remaining phenotypic response such as serum stress, ER stress, ionic stress, and membrane stress in presence of Ses. For this, we performed phenotypic susceptibility tests in the absence (control) and presence of Ses under the conditions which require
TABLE 2: $\mathrm{MIC}_{80}$ of C. albicans and non-albicans in presence of Ses at alkaline $\mathrm{pH}$.

\begin{tabular}{lcc}
\hline Strains & $\mathrm{pH}$ & $\mathrm{MIC}_{80}(\mathrm{mg} / \mathrm{mL})$ \\
\hline ATCC10261 & 10 & 0.552 \\
ATCC24433 & 10 & 0.552 \\
C. krusei & 8 & 0.828 \\
C. glabrata & 10 & 0.828 \\
C. parapsilosis & 8 & 1.104 \\
C. tropicalis & 10 & 0.552 \\
\hline
\end{tabular}

functional calcineurin signaling pathway. We observed that unlike control cells (Figure 5(a)) and similar to the alkaline $\mathrm{pH}$ (Figure 5(b)), C. albicans was unable to grow when treated with $50 \%$ serum along with the Ses (Figure 5(c)). Similar 


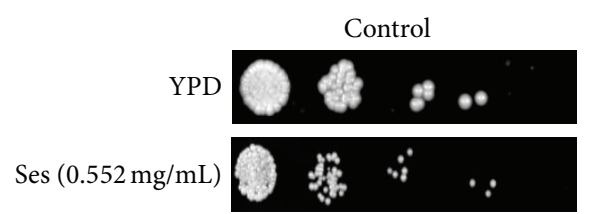

(a)

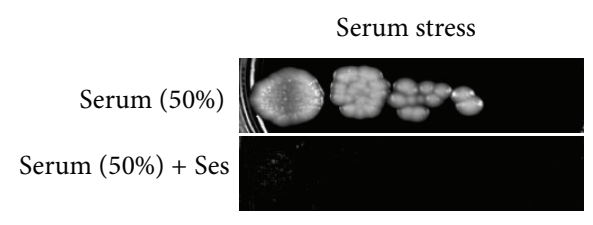

(c)

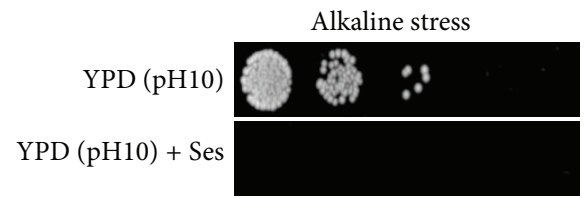

(b)

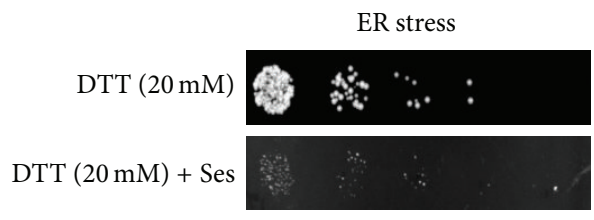

(d)

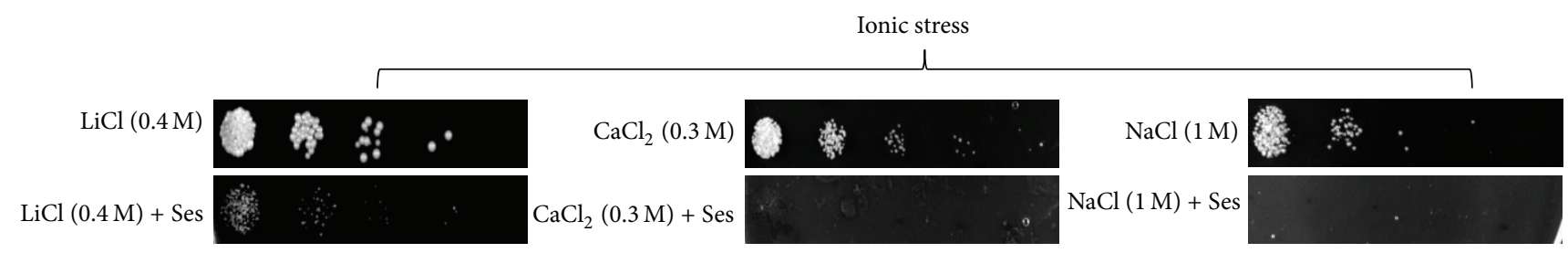

(e)

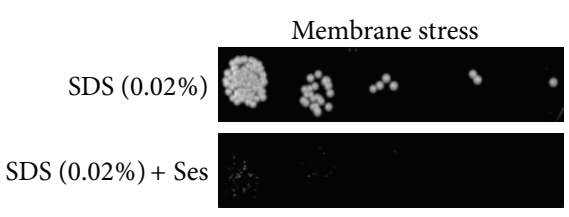

(f)

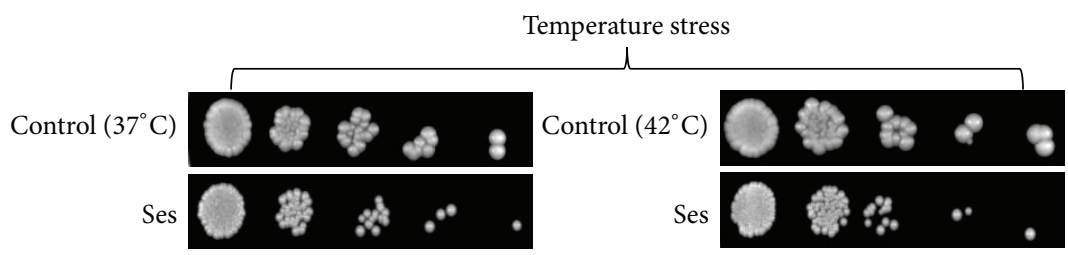

(g)

Figure 5: Phenotypic susceptibility assays to reveal the effect of Ses on the calcineurin dependent phenotypes in C. albicans. (a) Spot assay with and without Ses $(0.552 \mathrm{mg} / \mathrm{mL}$ ) as controls. (b) Spot assay with Ses at elevated $\mathrm{pH} 10$ showing hypersensitivity to C. albicans. (c) Spot assay depicting the loss of growth in cells treated with serum (50\% w/v) along with Ses. (d) Spot assay showing loss of growth under ER stress by DTT $(20 \mathrm{mM})$ in presence of Ses. (e) Spot assays showing sensitivity in the presence of Ses under various ionic stress conditions with $\mathrm{LiCl}(0.4 \mathrm{M}), \mathrm{CaCl}_{2}(0.3 \mathrm{M})$, and $\mathrm{NaCl}(1 \mathrm{M})$. (f) Spot assay demonstrating the attenuated growth of $C$. albicans in the presence of Ses with membrane perturbing agent SDS $(0.02 \% \mathrm{w} / \mathrm{v})$. (g) Spot assay demonstrating no growth loss at elevated temperature at $37^{\circ} \mathrm{C}$ and $42^{\circ} \mathrm{C}$ in the presence of Ses.

hypersensitive response to Ses was observed when treated with the DTT that is known to provide ER stress to the cells (Figure 5(d)). Next we study the salinity stress response and we observed that $C$. albicans was also unable to grow in presence of Ses when treated with the elevated doses of various salts, namely, $\mathrm{Na}^{+}, \mathrm{Ca}^{++}$, and $\mathrm{Li}^{+}$providing ionic stress to the cells (Figure 5(e)). Furthermore, the membrane stress response was tested by treating $C$. albicans with SDS and we observe a similar hypersensitivity in presence of Ses (Figure 5(f)). Notably, the cells in presence of Ses were showing resistance at elevated temperatures of 37 and $42^{\circ} \mathrm{C}$ and were efficiently growing (Figure $5(\mathrm{~g})$ ). Thus, our results demonstrate that Ses could possibly cause hindrance in the calcineurin signaling pathway in C. albicans.

3.5. Ses Causes Membrane Disruption in C. albicans. Hypersensitivity of $C$. albicans to Ses under the membrane stress, namely, SDS, necessitated further exploring the effect of Ses on membrane composition. For this, we estimated the ergosterol level which is the main component of the fungal cell membrane in the absence and presence of Ses. Interestingly, the Candida cells treated with Ses show dwindling in the ergosterol content to a significant level ( $P$ value $\leq 0.05)$ by around 63\% (Figures 6(a) and 6(b)). Furthermore, we assessed the micrographic images through transmission electron microscopy (TEM) that also confirmed the membrane disruption because of Ses treatment (Figure 6(c)).

3.6. Ses Does Not Cross Talk with Cell Wall Integrity Pathway in C. albicans. Cell wall integrity pathway (CWI) has been linked to calcineurin signaling pathway for having implications in governing responses toward survival of exposure to antifungal drugs [18]. To test whether Ses is affecting the cell wall integrity, we performed spot assays in presence of cell wall disrupting agents, namely, CFW and CR. Our results revealed that Ses was unable to affect the cell wall silhouette when administered along with the cell wall disrupting agents and the cell growth was not affected (Figure $7(\mathrm{a})$ ). The fact that Ses does not cause any cell mutilating effect was further confirmed by SEM experiments as described in Materials 


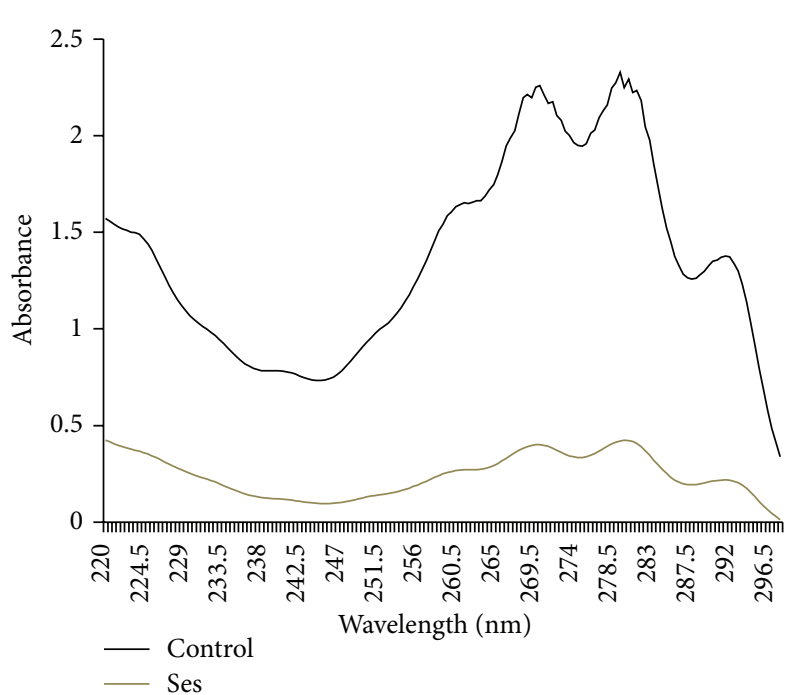

(a)

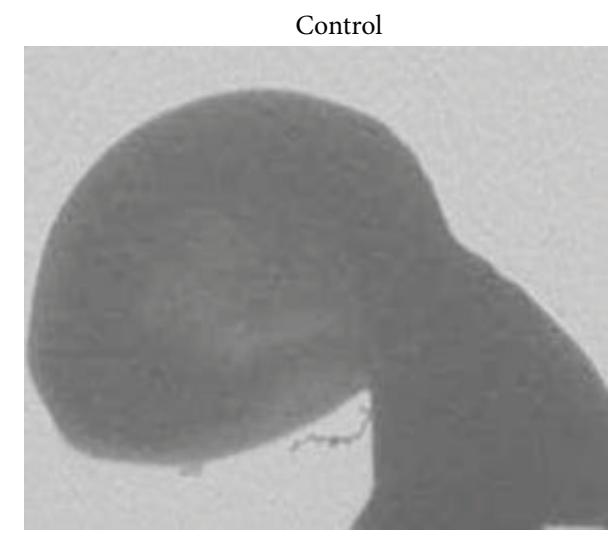

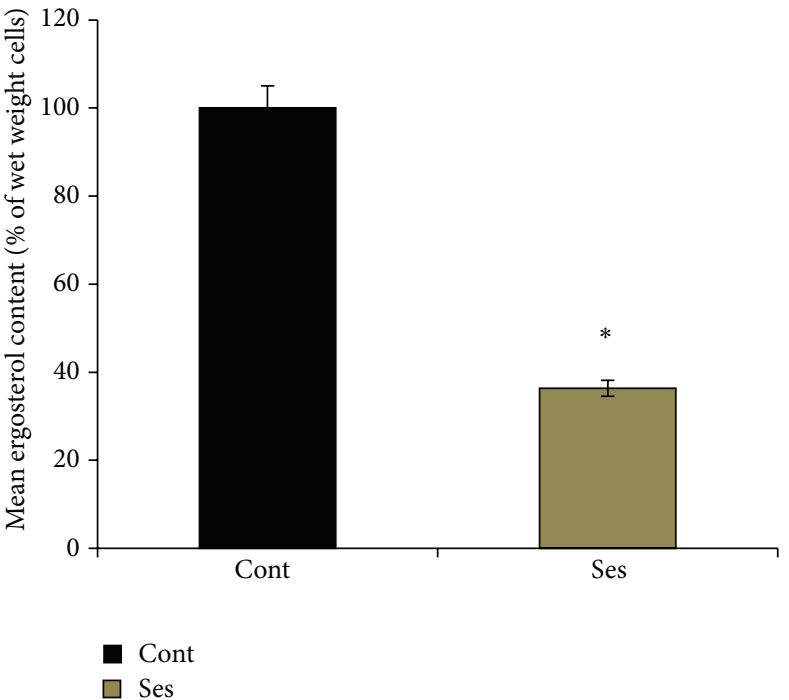

(b)

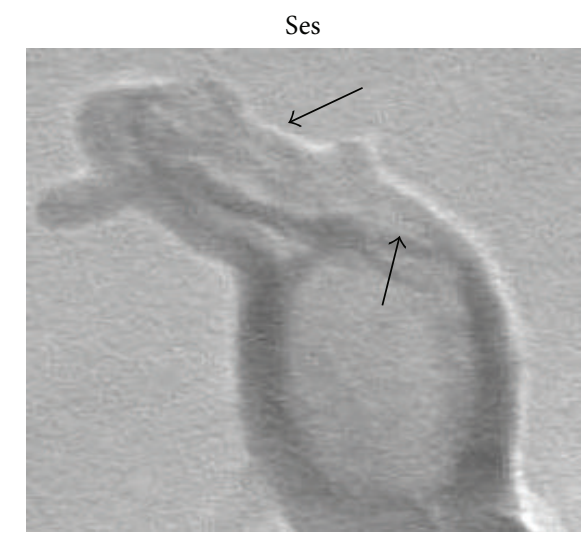

(c)

FIGURE 6: Effect of Ses on membrane composition. (a) UV spectrophotometric sterol profile of C. albicans scanned between 220 and $300 \mathrm{~nm}$ from a culture grown for 16 hours with and without Ses $(0.552 \mathrm{mg} / \mathrm{mL})$. (b) Relative percentages of ergosterol content in the absence (control) and presence of Ses $(0.552 \mathrm{mg} / \mathrm{mL})$. Mean of \% ergosterol levels is calculated as described in Section 2 normalized by considering the untreated control as 100 (absolute value of 0.003$) \pm$ SD of three independent sets of experiments are depicted on $y$-axis and $*$ depicts $P$ value $<0.05$. (c) Transmission electron micrographic image showing the tampered membrane integrity of C. albicans with or without Ses as described in Section 2 .

and Methods (Figure 7(b)). These results confirm that the anticandidal effect of Ses could not be associated with the corrugation of its cell surface morphology.

\section{Discussion}

Ses, the major constituent of sesame seed oil obtained from Sesamum sp., is a traditionally used supplement drug having antioxidant, anti-inflammatory, immunomodulatory, neuroprotective, antiaging, chemopreventive, proapoptotic, and antidepressant effects $[19,20]$. Recently, it was shown that Ses also suppresses the effect of cyclooxygenase- 2 transcriptional activity in colon cancer cells [21] which can be an important therapeutic intervention for cancer patients. The toxicological effects of sesamol have already been studied by Ambrose et al. [22] and found to be nontoxic and nonirritant and even do not cause skin sensitization. Despite the fact that Ses possesses such diverse ranges of properties for human benefits mentioned above, no direct study on its antifungal activity has been demonstrated. Hence, in this study we explore the antifungal potential and the mode of action of Ses against human fungal pathogen, C. albicans. We proposed that the effect of Ses against C. albicans might be mediated through stalled calcineurin signaling pathway leading to distorted membrane composition via ergosterol depletion. However, the antifungal effect of Ses is not affected by the multidrug efflux transporter or passive diffusion through membrane which are somewhat well-known mechanisms of action. Most of these mechanisms are critical for the virulence of C. albicans to survive within the host body $[17,23,24]$.

Firstly, we evaluated the antifungal activity of Ses through drug susceptibility testing; spot assay, disc diffusion assay, 


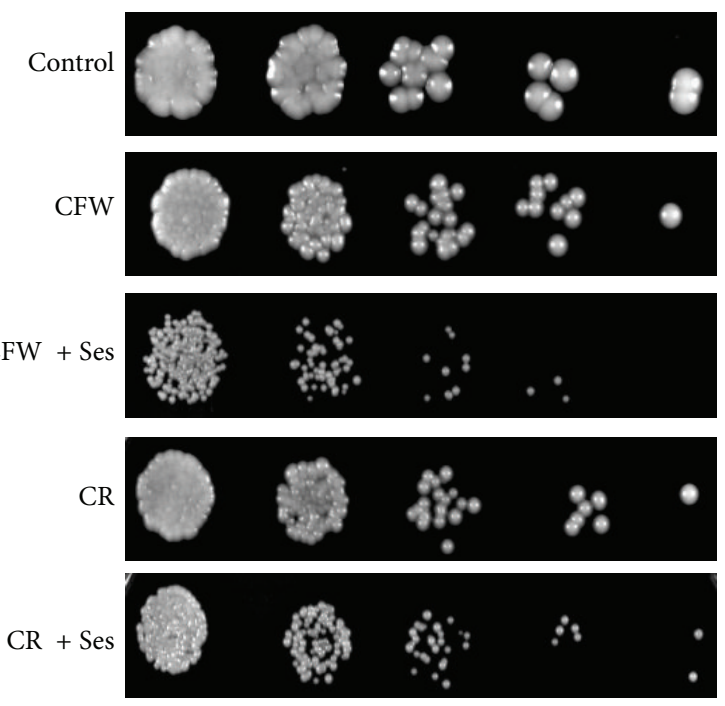

(a)
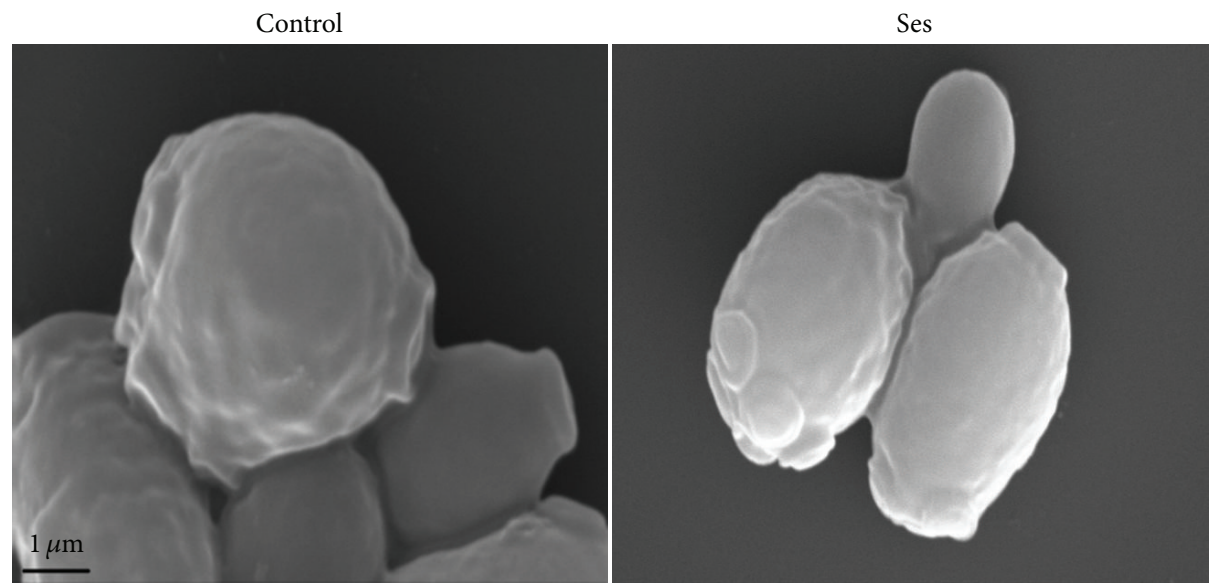

(b)

Figure 7: Effect of Ses on the cell wall integrity of C. albicans. (a) Spot assay showing no effect to Ses $(0.552 \mathrm{mg} / \mathrm{mL})$ in the presence of cell wall perturbing agents; CFW $(10 \mu \mathrm{g} / \mathrm{mL})$ and CR $(10 \mu \mathrm{g} / \mathrm{mL})$. (b) Scanning electron micrographs, as described in Section 2, showing the smooth surface of untreated cells (control) and treated cells.

and $\mathrm{MIC}_{80}$. Interestingly, we found that the growth of not only C. albicans but also non-albicans species of Candida was affected when grown in presence of Ses (Figures 1 and 2). These results prompted us to further examine the possible mode of action of Ses. Since the overexpression of drug efflux pumps is among the most common mechanisms responsible for the drug resistance in most of the fungi $[6,25]$, we checked if Ses is targeting MDR efflux transporter and passive diffusion in $C$. albicans through $\mathrm{R} 6 \mathrm{G}$ efflux assay. It was observed that the efflux as well as passive diffusion of R6G remains unaffected in presence of Ses in C. albicans (Figure 3). These results assured us that the efficacy of Ses is not linked with these activities but rather have a distinct mode of action. So, we further investigated other pathways by which it could affect the growth of C. albicans. One of the most important factors responsible for the virulence and survival of $C$. albicans inside the host body is its survival in varying $\mathrm{pH}$ ranges $[26,27]$. So the drug susceptibility testing of C. albicans at elevated $\mathrm{pH}$ in presence of Ses was performed and found that $C$. albicans as well as non-albicans species became hypersensitive to Ses at elevated $\mathrm{pH}$. Interestingly, hypersensitivity was observed at much lower concentrations than the ones used at physiological $\mathrm{pH}$ as shown in Figure 4. It is noteworthy that, for C. krusei and C. parapsilosis, the alkaline $\mathrm{pH}$ response was studied at $\mathrm{pH} 8.0$ since they were already hypersensitive at $\mathrm{pH} 10$ and we could not differentiate any further differences in sensitivity due to Ses (data not shown). Notably, unlike C. krusei which was hypersensitive at $\mathrm{pH}$ 8.0, sensitivity of C. parapsilosis remained unaffected in presence of Ses. The hypersensitive response of $C$. albicans in presence of Ses provided us with the inkling that antifungal mechanism of Ses has some relation with calcineurin signaling cascade as it is well known that alkaline $\mathrm{pH}$ is one of the several phenotypes governed via calcineurin signaling pathway [28-30].

Calcineurin pathway is an effective drug target which acts through $\mathrm{Ca}^{2+} /$ calmodulin activation based Ser/Thr dependent signaling pathway and is responsible for the 
virulence in $C$. albicans. Calcineurin is a dimeric protein that has remained highly conserved throughout the evolution in eukaryotes. Calcineurin includes a catalytic subunit CnA and a regulatory subunit $\mathrm{CnB}$. Calcineurin activates the Crzlp, a transcription factor [31], which interacts with nuclear localization signal (NLS) Nmd5p and translocates within the nucleus and encodes the products that help in the survival of the yeast during stress conditions [32] such as alkaline $\mathrm{pH}$ stress, ionic stress, membrane stress, endoplasmic reticulum stress, and serum stress [33]. Hypersensitive response of C. albicans towards Ses at alkaline $\mathrm{pH}$ and its association with calcineurin signaling pathway obligated us to analyze profundity the other phenotypes which are related to the functional calcineurin pathway.

To confirm our hypothesis that the antifungal effect of Ses is because of the compromised calcineurin pathway, $C$. albicans was administered with different stress conditions in presence of Ses that crucially requires functional calcineurin cascade. Some of the stresses other than alkaline $\mathrm{pH}$ are serum stress, ER stress, ionic stress, membrane stress, and thermal stress. As a known fact, after invading the host body, first situation that $C$. albicans faces is the encounter with blood. Blankenship and Heitman [34] have already reported that the serum component of the blood causes the stress and is toxic to C. albicans. This stress is efficiently survived by the functional calcineurin signaling pathway [1]. Therefore, we study the effect of Ses on C. albicans in presence of serum and observed the attenuated growth of Candida cells at 50\% concentration serum with Ses (Figure 5(c)). Likewise, ER stress is another parameter that leads to the activation of calcineurin signaling pathway by accumulating the unfolded proteins through the unfolded protein response (UPR) in eukaryotic cells [35]. Lately, Miyazaki and Kohno [36] have reported that UPR is also responsible for virulence which consequently activates calcineurin pathway in C. albicans but not in C. glabrata that lacks the fungal UPR and possesses a typical and unique alternate mechanism to evade ER stress. To observe the ER stress response, Candida cells were grown in the presence of DTT which could stimulate the formation of UPR by hindering N-linked glycosylation of secreted protein and inhibit the formation of disulfide bond in ER [37]. We found that Candida cells were hypersensitive in presence of ER stress as shown in Figure 5(d). Ionic stress response is reportedly another parameter by which we can study the calcineurin pathway [35]. We found that the ions, namely, $\mathrm{CaCl}_{2}, \mathrm{LiCl}$, and $\mathrm{NaCl}$, in presence of Ses checked the growth of C. albicans as illustrated in Figure 5(e). Similarly, it was found that Candida cell become hypersensitive when grown with membrane perturbing agent SDS in presence of Ses as in Figure 5(f). Another important factor that governs the activation of calcineurin signaling cascade in Candida as well as in other fungi is the thermotolerance. Interestingly, thermotolerance is not required for the activation of calcineurin in C. albicans but there are reports that prove its effects on the calcineurin in several other fungi as well as Candida sp. [24]. Hence, we assumed that there will be no effect of Ses on the elevated temperature stress at 37 and $42^{\circ} \mathrm{C}$ on C. albicans. As expected it was observed that irrespective of the presence of Ses, C. albicans cells were efficiently growing at higher temperature (Figure 5(g)). This data confirms the fact that thermal stress response is not governed by calcineurin signaling in C. albicans and Ses being primarily targeting the calcineurin signaling also has no influence on thermotolerance.

Perturbation of membrane structure and function was further evident from the fact that ergosterol levels were considerably reduced by around $63 \%$ in C. albicans when grown in presence of Ses (Figures 6(a) and 6(b)) which proves that Ses obliterates membrane veracity. This data is consistent with the fact that $C$. albicans cells were hypersensitive in presence of Ses when grown with membrane perturbing agent, namely, SDS (shown above). The disrupted membrane integrity of C. albicans in presence of Ses as also confirmed by TEM images (Figure 6(c)) clearly establishes the fact that Ses has destructive effect on membrane which could be possibly due to hindered calcineurin signaling pathway; however, further work is needed for confirmation.

Existence of evidence suggesting a crosstalk between calcineurin signaling cascade and cell wall integrity pathway [17, 23] and functional indispensability of calcineurin signaling cascade to sustain Ses exposure as demonstrated through this study necessitated to investigate the effect of Ses on cell wall damage. Intriguingly, there was no effect of Ses on cell wall damage when the cells were grown with the Ses along with cell wall perturbing agents, namely, CFW and CR (Figure 7(a)). This was further confirmed by performing SEM which shows the smooth surfaced cell wall when grown with or without Ses (Figure 7(b)). Thus, it could be said that the effective pathway by which Ses slays C. albicans is the disruption of cell wall integrity.

\section{Conclusion}

Despite the availability of various classes of antifungal drugs with enhanced activities, developments of drug resistance still remain a major concern for C. albicans. Thus, opting for an alternative therapeutic strategy by reverting towards natural compounds that can be used as antifungal agents could be a wise option. The data generated through this study clearly establishes the antifungal nature of Ses that can be exploited for improving the therapeutic strategies. Furthermore, these natural compounds could also hold promise to act as chemosensitizing agents that can be beneficial in reducing the dosages of current antifungal regimes.
Abbreviations
Ses: Sesamol
R6G: $\quad$ Rhodamine 6G
2-DOG: 2-Deoxy D-glucose
2,4 DNP: 2,4-Dinitrophenol
CFW: Calcofluor white
CR: $\quad$ Congo red
YEPD: $\quad$ Yeast extract peptone dextrose
TEM: Transmission electron microscopy
SEM: $\quad$ Scanning electron microscopy.

\section{Conflict of Interests}

The authors declare that there is no conflict of interests. 


\section{Acknowledgments}

Saif Hameed would like to thank the financial assistance in the form of Young Scientist Award (SR/FT/LS-12/2012) from Science and Engineering Research Board (SERB), New Delhi. The authors acknowledge the assistance of Jasvir Singh and Rita Salam, IARI, New Delhi, in TEM and SEM experiments. The authors are grateful to Luqman A. Khan and Nikhat Manzoor, Jamia Millia Islamia, New Delhi, for providing Candida reference strains as generous gift. The authors also thank Sumathi Muralidhar, Regional Sexually Transmitted Disease Research Centre, Safdarjung Hospital, New Delhi, for helping them with clinical isolates of C. albicans and nonalbicans strains. The authors thank Professor S. M. Paul Khurana, Dean of Faculty of Science, Engineering \& Technology, for encouragement and providing the available facilities for research in the institute.

\section{References}

[1] J. R. Blankenship, F. L. Wormley, M. K. Boyce et al., "Calcineurin is essential for Candida albicans survival in serum and virulence," Eukaryotic Cell, vol. 2, no. 3, pp. 422-430, 2003.

[2] C. M. Beck-Sague and W. R. Jarvis, "Secular trends in the epidemiology of nosocomial fungal infections in the United States, 1980-1990," The Journal of Infectious Diseases, vol. 167, no. 5, pp. 1247-1251, 1993.

[3] R. P. Wenzel, "Nosocomial candidemia: risk factors and attributable mortality," Clinical Infectious Diseases, vol. 20, no. 6, pp. 1531-1534, 1995.

[4] K. Neelofar, S. Shreaz, B. Rimple, S. Muralidhar, M. Nikhat, and L. A. Khan, "Curcumin as a promising anticandidal of clinical interest," Canadian Journal of Microbiology, vol. 57, no. 3, pp. 204-210, 2011.

[5] L. Coronado-Castellote and Y. Jiménez-Soriano, "Clinical and microbiological diagnosis of oral candidiasis," Journal of Clinical and Experimental Dentistry, vol. 5, no. 5, pp. e279-e286, 2013.

[6] R. Prasad and K. Kapoor, "Multidrug resistance in yeast Candida," International Review of Cytology, vol. 242, pp. 215-248, 2004.

[7] M. A. Bankole, L. A. J. Shittu, T. A. Ahmed et al., "Synergistic antimicrobial activities of phytoestrogens in crude extracts of two sesame species against some common pathogenic microorganisms," African Journal of Traditional, Complementary and Alternative Medicines, vol. 4, no. 4, pp. 427-433, 2007.

[8] J. S. Alencar, S. Pietri, M. Culcasi et al., "Interactions and antioxidant stability of sesamol in dry-emulsions," Journal of Thermal Analysis and Calorimetry, vol. 98, no. 1, pp. 133-143, 2009.

[9] K. Mukhopadhyay, A. Kohli, and R. Prasad, "Drug susceptibilities of yeast cells are affected by membrane lipid composition," Antimicrobial Agents and Chemotherapy, vol. 46, no. 12, pp. 3695-3705, 2002.

[10] T. Prasad, A. Chandra, C. K. Mukhopadhyay, and R. Prasad, "Unexpected link between iron and drug resistance of Candida spp.: iron depletion enhances membrane fluidity and drug diffusion, leading to drug-susceptible cells," Antimicrobial Agents and Chemotherapy, vol. 50, no. 11, pp. 3597-3606, 2006.

[11] National Committee for Clinical and Laboratory Standards, Reference Method for Broth Dilution Antifungal Susceptibility Testing of Yeasts, vol. 28, no. 14, Approved standard M27-A3,
National Committee for Clinical and Laboratory Standards, Wayne, Ill, USA, 2008.

[12] T. Prasad, S. Hameed, R. Manoharlal et al., "Morphogenic regulator EFG1 affects the drug susceptibilities of pathogenic Candida albicans," FEMS Yeast Research, vol. 10, no. 5, pp. 587-596, 2010.

[13] S. Shukla, P. Saini, S. Jha, S. V. Ambudkar, and R. Prasad, "Functional characterization of Candida albicans $\mathrm{ABC}$ transporter Cdrlp," Eukaryotic Cell, vol. 2, no. 6, pp. 1361-1375, 2003.

[14] B. A. Arthington-Skaggs, H. Jradi, T. Desai, and C. J. Morrison, "Quantitation of ergosterol content: novel method for determination of fluconazole susceptibility of Candida albicans," Journal of Clinical Microbiology, vol. 37, no. 10, pp. 3332-3337, 1999.

[15] O. N. Breivik and J. L. Owades, "Spectrophotometric semimicrodetermination of ergosterol in yeast," Agricultural and Food Chemistry, vol. 5, no. 5, pp. 360-363, 1957.

[16] Y.-L. Chen, A. Brand, E. L. Morrison et al., "Calcineurin controls drug tolerance, hyphal growth, and virulence in Candida dubliniensis," Eukaryotic Cell, vol. 10, no. 6, pp. 803-819, 2011.

[17] A. Kumar, S. Dhamgaye, I. K. Maurya, A. Singh, M. Sharma, and R. Prasad, "Curcumin targets cell wall integrity via calcineurinmediated signaling in Candida albicans," Antimicrobial Agents and Chemotherapy, vol. 58, no. 1, pp. 167-175, 2014.

[18] S. L. LaFayette, C. Collins, A. K. Zaas et al., "PKC signaling regulates drug resistance of the fungal pathogen Candida albicans via circuitry comprised of mkcl, calcineurin, and Hsp90," PLoS Pathogens, vol. 6, no. 8, Article ID e1001069, 2010.

[19] P. Hassanzadeh, E. Arbabi, and F. Rostami, “The ameliorative effects of sesamol against seizures, cognitive impairment and oxidative stress in the experimental model of epilepsy," Iranian Journal of Basic Medical Sciences, vol. 17, no. 2, pp. 100-107, 2014.

[20] R. M. Thushara, M. Hemshekhar, M. Paul et al., "Crocin prevents sesamol-induced oxidative stress and apoptosis in human platelets," Journal of Thrombosis and Thrombolysis, vol. 38, no. 3, pp. 321-330, 2014.

[21] S. Shimizu, G. Fujii, M. Takahashi et al., "Sesamol suppresses cyclooxygenase- 2 transcriptional activity in colon cancer cells and modifies intestinal polyp development in $\mathrm{Apc}^{\mathrm{Min} /+}$ mice," Journal of Clinical Biochemistry and Nutrition, vol. 54, no. 2, pp. 95-101, 2014.

[22] A. M. Ambrose, A. J. Cox Jr., and F. DeEds, "Antioxidant toxicity: toxicological studies on sesamol," Journal of Agricultural and Food Chemistry, vol. 6, no. 8, pp. 600-604, 1958.

[23] C. A. Munro, S. Selvaggini, I. de Bruijn et al., "The PKC, HOG and $\mathrm{Ca}^{2+}$ signalling pathways co-ordinately regulate chitin synthesis in Candida albicans," Molecular Microbiology, vol. 63, no. 5, pp. 1399-1413, 2007.

[24] Y. L. Chen, J. H. Konieczka, D. J. Springer et al., "Convergent evolution of calcineurin pathway roles in thermotolerance and virulence," G3 Journal, vol. 2, no. 6, pp. 675-691, 2012.

[25] S. Hameed and Z. Fatima, "Novel regulatory mechanisms of pathogenicity and virulence to combat MDR in Candida albicans," International Journal of Microbiology, vol. 2013, Article ID 240209, 10 pages, 2013.

[26] D. Davis, "Adaptation to environmental $\mathrm{pH}$ in Candida albicans and its relation to pathogenesis," Current Genetics, vol. 44, no. 1, p. 58, 2003.

[27] K. Selvig and J. A. Alspaugh, "pH response pathways in fungi: adapting to host-derived and environmental signals," Mycobiology, vol. 39, no. 4, pp. 249-256, 2011. 
[28] A. L. Kullas, S. J. Martin, and D. Davis, "Adaptation to environmental $\mathrm{pH}$ : integrating the Rim101 and calcineurin signal transduction pathways," Molecular Microbiology, vol. 66, no. 4, pp. 858-871, 2007.

[29] H. Wang, Y. Liang, B. Zhang, W. Zheng, L. Xing, and M. Li, "Alkaline stress triggers an immediate calcium fluctuation in Candida albicans mediated by Rim101p and Crzlp transcription factors," FEMS Yeast Research, vol. 11, no. 5, pp. 430-439, 2011.

[30] S. Hameed, S. Dhamgaye, A. Singh, S. K. Goswami, and R. Prasad, "Calcineurin signaling and membrane lipid homeostasis regulates iron mediated multidrug resistance mechanisms in Candida albicans," PLoS ONE, vol. 6, no. 4, Article ID e18684, 2011.

[31] A. Stathopoulos-Gerontides, J. J. Guo, and M. S. Cyert, "Yeast calcineurin regulates nuclear localization of the Crzlp transcription factor through dephosphorylation," Genes and Development, vol. 13, no. 7, pp. 798-803, 1999.

[32] M. S. Cyert, "Calcineurin signaling in Saccharomyces cerevisiae: how yeast go crazy in response to stress," Biochemical and Biophysical Research Communications, vol. 311, no. 4, pp. 11431150, 2003.

[33] H. Yan, Y. Zhao, and L. Jiang, "The putative transcription factor CaRtg3 is involved in tolerance to cations and antifungal drugs as well as serum-induced filamentation in Candida albicans," FEMS Yeast Research, vol. 14, no. 4, pp. 614-623, 2014.

[34] J. R. Blankenship and J. Heitman, "Calcineurin is required for Candida albicans to survive calcium stress in serum," Infection and Immunity, vol. 73, no. 9, pp. 5767-5774, 2005.

[35] J. Zhang, J. Heitman, and Y. L. Chen, "Comparative analysis of calcineurin signaling between Candida dubliniensis and Candida albicans," Communicative and Integrative Biology, vol. 5, no. 2, pp. 122-126, 2012.

[36] T. Miyazaki and S. Kohno, "ER stress response mechanisms in the pathogenic yeast Candida glabrata and their roles in virulence," Virulence, vol. 5, no. 2, pp. 365-370, 2014.

[37] M. Bonilla, K. K. Nastase, and K. W. Cunningham, "Essential role of calcineurin in response to endoplasmic reticulum stress," The EMBO Journal, vol. 21, no. 10, pp. 2343-2353, 2002. 


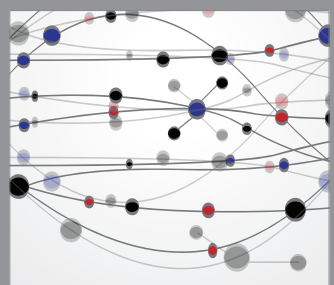

The Scientific World Journal
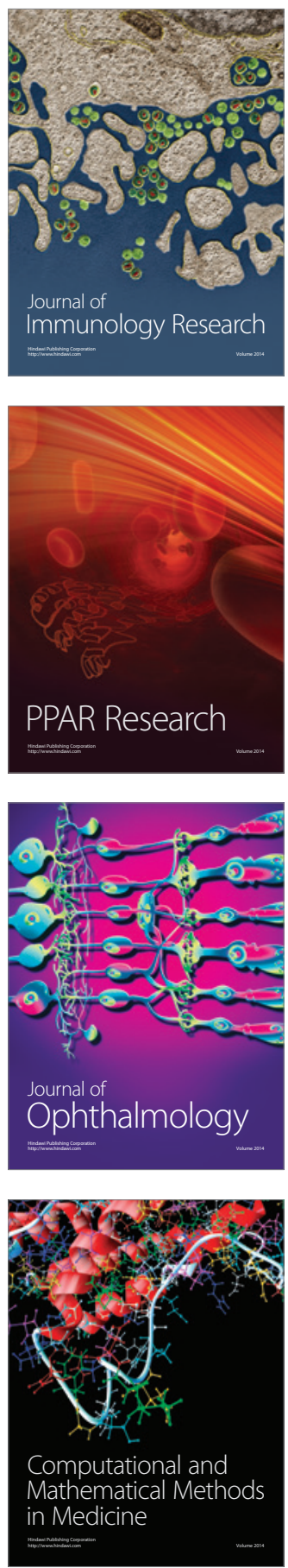

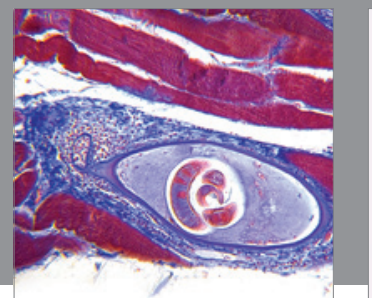

Gastroenterology

Research and Practice
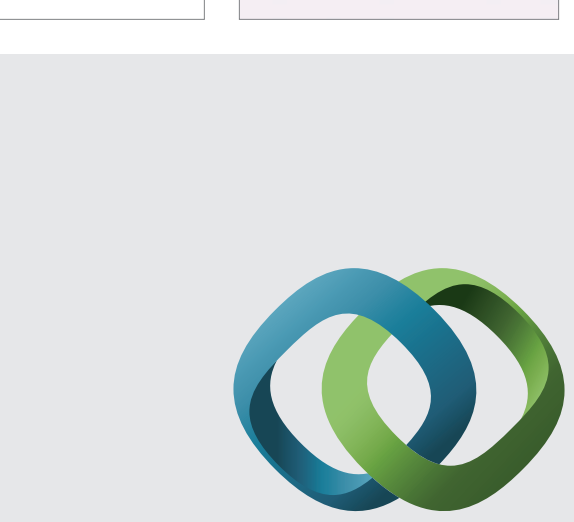

\section{Hindawi}

Submit your manuscripts at

http://www.hindawi.com
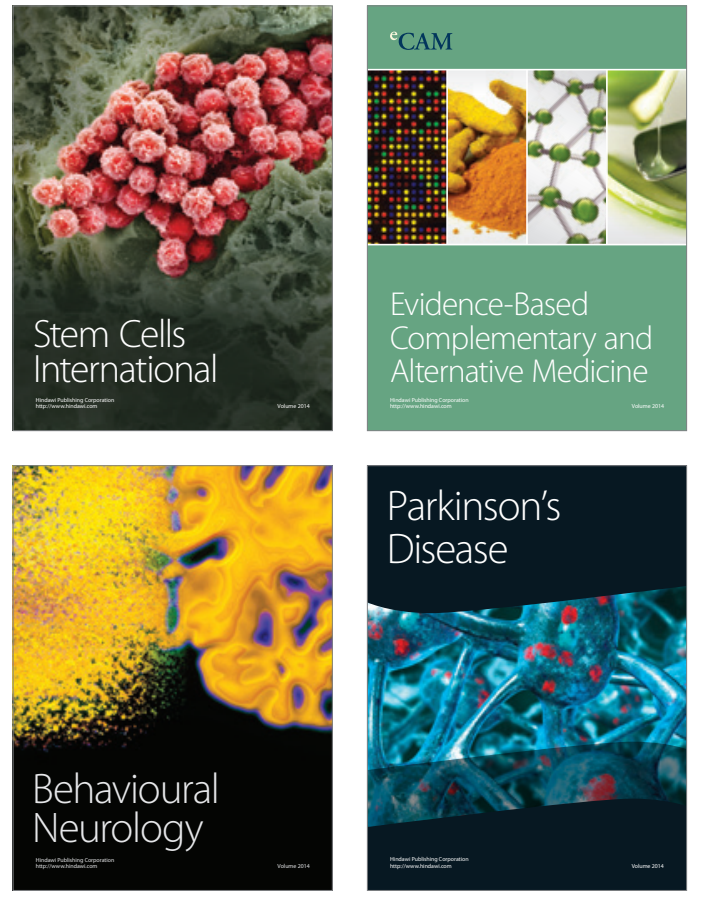
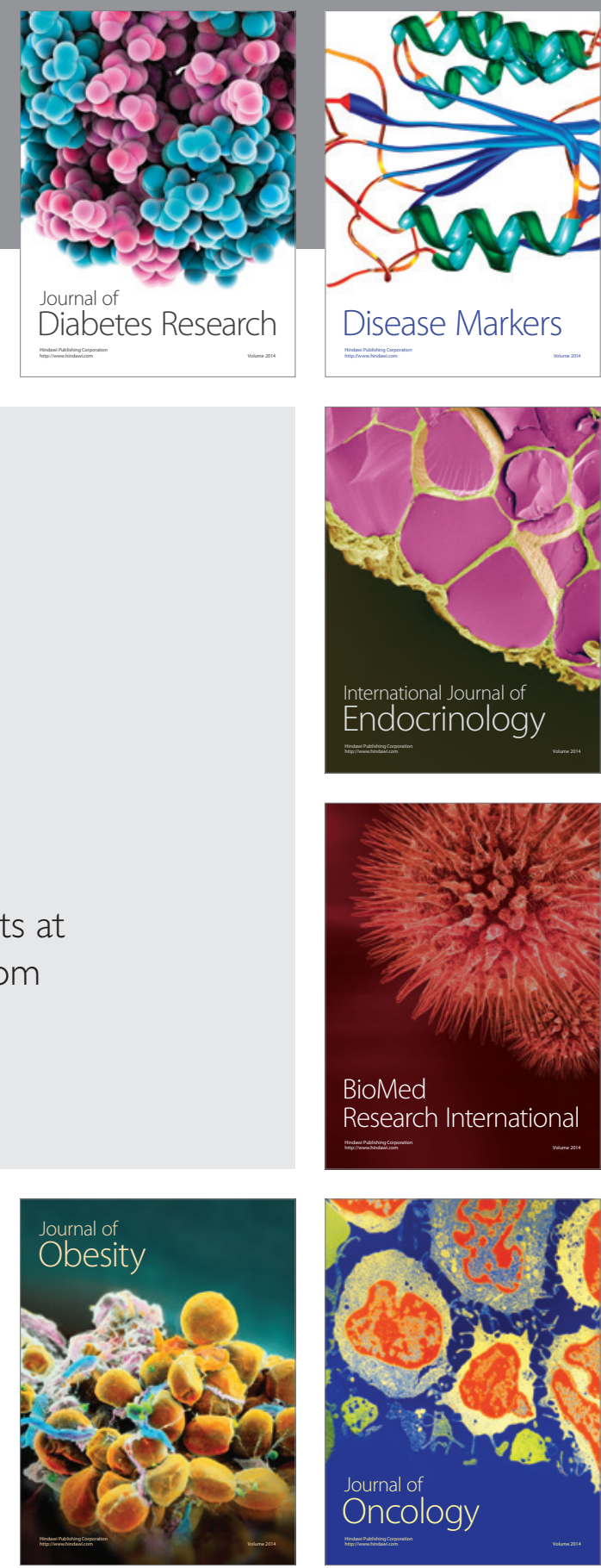

Disease Markers
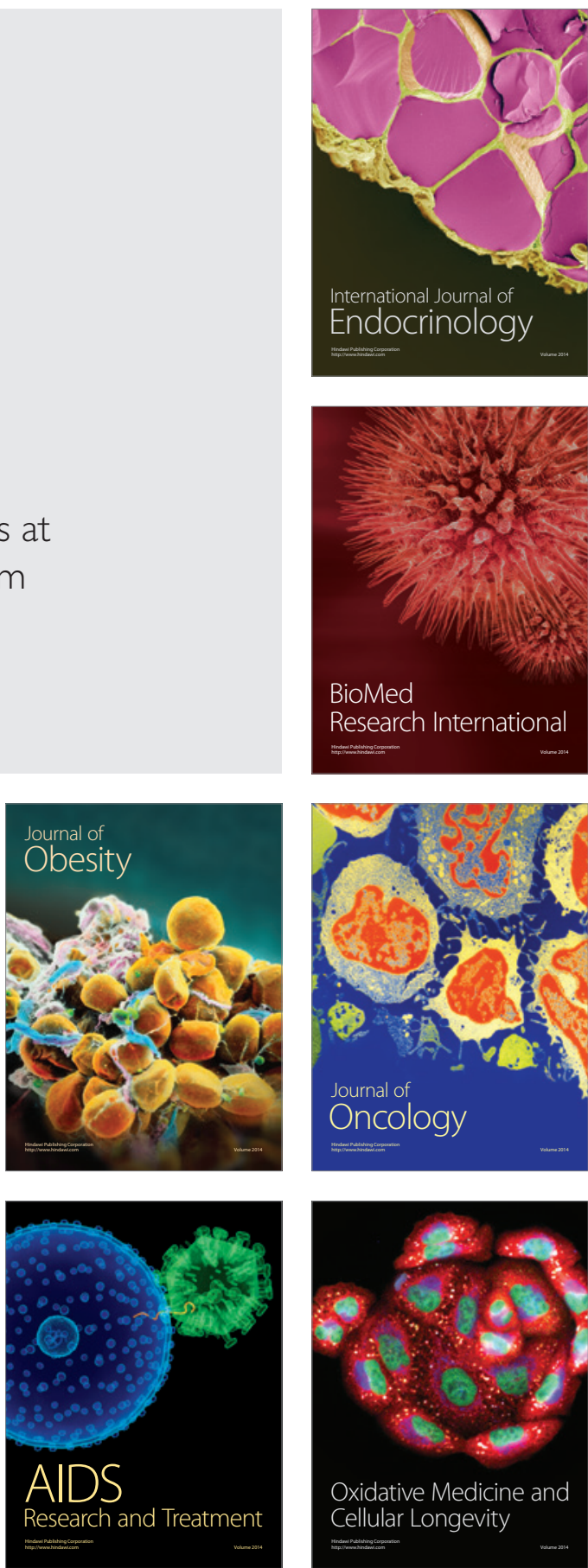